\title{
Spectrum of Perforation Peritonitis at Tertiary Center: An Institutional Experience
}

\author{
Authors \\ Dr Hemant Kumar Beniwal ${ }^{1}$, Dr Jeetendra Sakhrani², Dr Ashok Parmar ${ }^{3}$, \\ Dr Abhijeet Beniwal ${ }^{4}$, Dr Anisha ${ }^{5}$, Dr Isha Karwasra ${ }^{6}$, Dr Dheeraj Godara ${ }^{7}$ \\ ${ }^{1}$ MS Gen Surgery, SR SPMC Bikaner, ${ }^{2}$ MS Gen Surgery \\ ${ }^{3}$ Sr Proff. Dept. of Gen Surgery, ${ }^{4,6,7}$ SR Gen Surgery, SPMC Bikaner \\ ${ }^{5}$ Resident anesthesia, SMS Jaipur
}

\begin{abstract}
Peritonitis due to perforation of the gastrointestinal tract is the most common surgical emergency all over the world.

The etiological spectrum of perforation peritonitis in India differs significantly from its western counter parts. We conducted a study of 217 patients in duration of one year at tertiary center in north west Rajasthan. All patients were >14years of age. Blunt trauma abdomen were excluded from the study. Along with spectrum of perforation peritonitis, demographic features, etiology, intraoperative finding, operative procedure, morbidity and mortality are also studied.

The mean age at presentation was $44.36 \pm 18.30$ years (range from 14 to 89 years). Majority of patients are male $82.9 \%$ and from rural area $93.5 \%$. Male to Female ratio 4.86:1. Most of them presented with history of smoking (72.8\%), NSAIDS intake (67.7\%). Perforation sites were: duodenum-33.8\%, ileal (25.8\%), gastric and prepyloric (24.4\%), appendicular (7.8\%), jejunal (4.6\%) and colonic (1.8\%). Morbidity $36.86 \%$ and mortality $5.52 \%$.

It is concluded that upper gastrointestinal (UGI) perforations are more common in this study which is comparable to studies in the region. Alcohol abuse, smoking, and NSAIDS are the main etiological factors. Prevention of absue of all these substances can considerably decrease the incidence of UGI perforations.

Keywords: Spectrum, Perforation Peritonitis , Incidence, Prevention.
\end{abstract}

\section{INTRODUCTION}

Peritonitis is an inflammation of the peritoneum, the tissue that lines the inner wall of the abdomen and covers and supports most of abdominal organs. Perforation peritonitis is a surgical emergency which is frequently encountered in tropical countries like India. It commonly affects young male population, if comparision is done with the studies in the west ${ }^{[1]}$ where the mean age of cases is between 45-60 years. In majority, cases present late to the hospital with well established generalized peritonitis with purulent or fecal contamination and septicemia of varying degree. The signs and symptoms of almost all cases of perforation peritonitis are typical and clinical diagnosis of peritonitis can be made in all patients. X-ray FPA, ultrasound abdomen and CT scan are the investigations that can confirm the 
diagnosis. However diagnostic laparoscopy also can be helpful in some of cases.

Peritonitis usually presents as an acute abdomen. Local findings include generalised abdominal tenderness, guarding, rigidity, abdominal distension, decreased bowel sounds. Systemic findings include fever with chills or rigor, restlessness, tachycardia, tachypnea, dehydration, oliguria, disorientation and ultimately shock $^{[3]}$. Prognosis affecting factors are age, vitals, metabolic acidosis, malnutrition, personal habbits of smoking, alcoholism and drug abuse, preoperative status, serum albumin, malignoma, cause of infection, site of origin of peritonitis, contamination in peritoneal cavity. Left untreated, peritonitis can rapidly spread into the blood (sepsis) and to other organs, resulting in multiple organ failure and death.

The spectrum of gastrointestinal perforation is having a wide geographical variations; in western countries with preponderance of lower gastrointestinal perforations as opposed to upper gastrointestinal perforations in developing countries $^{[11],[12],[14],[15]}$. The etiological spectrum of perforation peritonitis in India differs significantly from its western counter parts. Majority of the patients present late, with purulent peritonitis and septicemia. Thus surgical management of perforation peritonitis becomes highly demanding and more complex. A combination of anti microbial therapy, improved surgical technique, and intensive care support may improve the outcome of such cases.

\section{AIMS AND OBJECTIVES}

To study the spectrum of perforation peritonitis at tertiary center in north west Rajasthan along with demographic features, etiology, intra-operative findings, operative procedures, postoperative morbidity and mortality.

\section{MATERIAL AND METHODS}

This prospective study was conducted in the department of general surgery, from $1^{\text {st }}$ December 2014 to $30^{\text {th }}$ November 2015 at S.P. Medical
College and P.B.M. Associated Group of Hospitals, Bikaner in north west Rajasthan. Total 217 patients of perforation peritonitis were studied in duration of one year. Patients with perforation peritonitis diagnosed clinically and ascertained by Gas Under Diaphragm in X-ray FPA and free fluid in peritoneal cavity in USG abdomen will be included in the study. All cases of paediatric age group (age < 14 years) and Perforation peritonitis due to Blunt Trauma Abdomen were excluded from study. Spectrum of perforation peritonitis is studied based on intraoperative finding of site of perforation. According to site of perforation, intra-abdominal contamination and haemodynamic status of patient definitive procedure is done. Other parameters included in aims and objective are also studied along with outcome of cases.

\section{OBSERVATION}

In our study, the mean age was $44.36 \pm 18.30$ years (range from 14 to 89 years). Majority of patients are male $82.9 \%$ and majority of patients from rural area $93.5 \% .100 \%$ patients presented with complaint of pain abdomen with associated complaints of nausea and vomiting in $88 \%$, and distention of abdomen in $63.6 \%$. On basis of personal history of $67.7 \%$ patients had positive history of NSAIDs intake, $23 \%$ patients having history of opioid addiction, $72.8 \%$ history of smoking, $58.5 \%$ patients had history of alcohol, $45 \%$ patients had history of spicy food, $11.5 \%$ had history of stress factor. In our study $94.5 \%$ patients had Gas Under Diaphragm on X-ray flate plate abdomen. On USG abdomen $65.4 \%$ patients had moderate free fluid while $34.6 \%$ patients had mild free fluid. All preoperative datas are shown in table 1. After making diagnosis of perforation peritonitis based on history, clinical examination and radiological examination, abdomen is opened, thorough peritoneal wash is done and perforation site is found on gastrointestinal tract. Intraoperative photograph of peptic perforation is attached in manuscript under title of 'Fig 1 Peptic Perforation'. 
In spectrum of perforation peritonitis, in this study most common site of perforation is found gastroduodenal (58\%), in which duodenal perforation was more common. Commonest site of perforation is duodenum (33.6\%), followed by ileal $(25.8 \%)$, gastric and prepyloric $(24.4 \%)$, appendicular (7.8\%), jejunal (4.6\%) and colonic $(1.8 \%)$.Surgical procedure done for perforation most commonly is omental patch repair in $121(55.8 \%)$ cases, followed by primary repair of perforation $43(19.8 \%)$, ileostomy 30(13.8\%), appendectomy 9(4.1\%), colostomy 7(3.3\%), resection anastomosis 5(2.3\%) and gastrojejunostomy $2(0.9 \%)$. All intraoperative data are shown in table 2. After definitive procedure of perforation a wide bore drain is placed in abdominal cavity and abdomen is closed. Mean duration of hospital stay is $8.73 \pm 1.52$ days.

In our study postoperative complications were present in 80 cases $(36.86 \%)$. In postoperative complications wound infection 24(11.05\%), pneumonia 19(8.75\%), abdominal collection $15(6.91 \%)$, septicemia $9(4.14 \%)$, burst abdomen $8(3.68 \%)$, acute renal failure $3(1.38 \%)$ and anastomotic leak 2(.92\%) was found. In 12 cases $(5.52 \%)$ mortality was found in this study. All postoperative data are shown in table 3.

TABLE - 1

\begin{tabular}{|l|c|}
\hline \multicolumn{2}{|l|}{ PREOPERATIVE DATA } \\
\hline AGE ( YEARS ) \\
$<50$ YEARS & $141(64.97)$ \\
$>50$ YEARS & $76(35.02)$ \\
\hline SEX & \\
MALE & $180(82.9)$ \\
FEMALE & $37(17.1)$ \\
\hline RESIDENCE & \\
RURAL & $203(93.5)$ \\
URBAN & $14(6.5)$ \\
\hline PERSONAL HABITS & \\
NSAIDS INTAKE & $147(67.7)$ \\
ALCOHOL INTAKE & $127(58.5)$ \\
SMOKING' & $158(72.8)$ \\
OPIOID INTAKE & $50(23)$ \\
SPICY FOOD & $47(20.7)$ \\
STRESS & $25(11.5)$ \\
\hline
\end{tabular}

\begin{tabular}{|l|c|}
\hline CHIEF COMPLAIN & \\
PAIN ABDOMEN & $217(100)$ \\
ABDOMINAL DISTENSION & $138(63.6)$ \\
NAUSEA AND VOMITING & $191(88.2)$ \\
CONSTIPATION & $78(35.94)$ \\
\hline X- RAY FLAT PLATE ABDOMEN & \\
GAS UNDER DIAPHRAGM PRESENT & $205(94.5)$ \\
GAS UNDER DIAPHRAGM ABSENT & $12(5.5)$ \\
\hline USG ABDOMEN & \\
MILD FREE FLUID & $75(34.6)$ \\
MODERATE FREE FLUID & $142(65.4)$ \\
\hline
\end{tabular}

\section{TABLE- 2}

\begin{tabular}{|l|c|}
\hline OPERATIVE DATA & FREQUENCY \\
\hline PARAMETER & (PERCENTAGE) \\
\hline SITE OF PERFORATION & \\
DUODENAL & $73(33.6)$ \\
ILEAL & $56(25.8)$ \\
GASTRIC \& PRE PYLORIC & $53(24.4)$ \\
APPENDICULAR & $17(7.8)$ \\
JEJUNAL & $10(4.6)$ \\
COLONIC & $8(3.6)$ \\
\hline SURGICAL PROCEDURES & \\
GRAHMS PATCH REPAIR & $121(55.8)$ \\
PRIMARY REPAIR (SIMPLE CLOSURE) & $43(19.8)$ \\
ILEOSTOMY & $30(13.8)$ \\
APPENDCECTOMY & $9(4.1)$ \\
COLOSTOMY & $7(3.3)$ \\
RESECTION AND ANASTOMOSIS & $5(2.3)$ \\
GASTEROJEJUNOSTOMY & $2(.9)$ \\
\hline
\end{tabular}

TABLE- 3

\begin{tabular}{|l|c|}
\hline \multicolumn{2}{|l|}{ POST OPERATIVE DATA } \\
\hline PARAMETERS & FREQUENCY \\
& (PERCENTAGE) \\
\hline MORBIDITY & \\
WOUND INFECTION & $24(11.05)$ \\
PNEUMONIA & $19(8.75)$ \\
ABDOMINLAL COLLECTION & $15(6.91)$ \\
SEPTICEMIA & $9(4.14)$ \\
BURST ABDOMEN & $8(3.68)$ \\
ACUTE RENAL FAILURE & $3(1.38)$ \\
ANASTOMOTIC LEAK & $2(.92)$ \\
\hline MORATALITY & $12(5.52)$ \\
\hline
\end{tabular}


TABLE - 4

\begin{tabular}{|l|c|c|c|c|c|c|}
\hline \multirow{2}{*}{ COMPARISON OF SPECTRUM OF PERFORATION PERITONITIS IN VARIOUS STUDIES } \\
\hline & \multicolumn{2}{|c|}{${\text { Jhobta et a }{ }^{15}}^{2}$} & \multicolumn{2}{|c|}{ Bali et al $^{16}$} & \multicolumn{2}{|c|}{ Present Study } \\
\cline { 2 - 8 } & No. & $\%$ & No. & $\%$ & No. & $\%$ \\
\hline DUODENAL & 289 & 57.3 & 150 & 37.5 & 73 & 33.6 \\
\hline STOMACH & 42 & 8.3 & 29 & 7.3 & 53 & 24.4 \\
\hline ILEAL & 76 & 15.1 & 90 & 22.5 & 56 & 25.8 \\
\hline JEJUNAL & 16 & 3.2 & 38 & 9.5 & 10 & 4.6 \\
\hline APPENDICULAR & 59 & 11.7 & 74 & 18.5 & 17 & 7.8 \\
\hline COLONIC & 19 & 3.8 & 19 & 4.7 & 8 & 3.6 \\
\hline ESOPHAGEAL & 3 & 0.6 & 0 & 0 & 0 & 0 \\
\hline TOTAL CASES & 504 & 100 & 400 & 100 & 217 & 100 \\
\hline
\end{tabular}

Fig. - Peptic Perforation

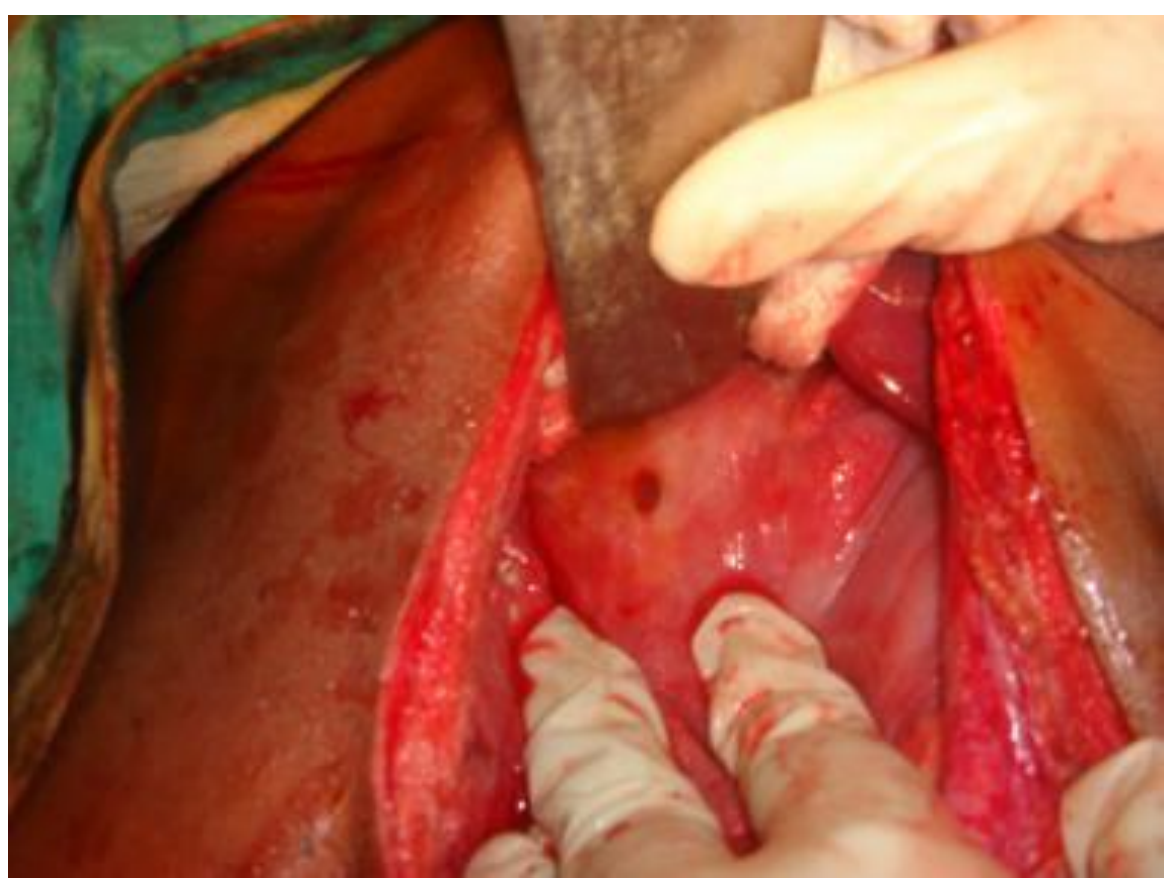

\section{DISCUSSION}

The perforation peritonitis of upper gastrointestinal tract is more common in tropical and developing countries. The perforations of proximal gastrointestinal tract were six times as common as perforations of distal gastrointestinal tract as has been noted in earlier studies from India $^{[4]}$, which is in sharp contrast to studies from developed countries like United States ${ }^{[6]}$,
Greece $^{[7]}$ and Japan ${ }^{[8]}$ which revealed that distal gastrointestinal tract perforations were more common.

In our study, the mean age was $44.36 \pm 18.30$ years (range from 14 to 89 years) which is supporting the presentation of perforation peritonitis comparatively at young age in tropical countries. In our study maximum cases of perforation peritonitis are male $(82.9 \%)$ and from rural 
area(93.5\%), due to heavy alcohol consumption, smoking, and inadvertent drug (NSAIDS) intake more in males and in rural area of this region. On the basis of personal history of patients of perforation peritonis $72.8 \%$ patients had history of smoking, $67.7 \%$ patients had positive history of NSAIDs intake, $58.5 \%$ patients had history of alcohol intake, $45 \%$ patients had history of spicy food, $23 \%$ patients having history of opioid addiction and $11.5 \%$ had history of stress factor. All of these factors are acting as causative agents of peptic ulcer which lead to peptic perforation, supporting as most common site of perforation in this study.

Peritonitis has a long historical background and is conventionally divided into three broad groups namely; primary, secondary and tertiary basing on the source and nature of the microbial contamination $^{[5]}$. Secondary peritonitis which is due to perforation of the gastrointestinal tract is one of the most common surgical emergencies all over the world and it is associated with significantly morbidity and mortality ${ }^{[9-12]}$. Due to the loss of epithelial integrity, bacterial pathogens can traverse into the peritoneal cavity leading to a cascade of inflammatory response, sepsis, multisystem organ failure and death if not treated in a timely manner ${ }^{[9]}$. Aggressive resuscitation and early surgical intervention is therefore required in order to deliver optimal care for the patients and improve their treatment outcome ${ }^{[10-}$ 13].

The spectrum of gastrointestinal perforation have a wide geographical variations; but in various studies of developing countries results are in favour of upper gastrointestinal perforation to be common as compare to lower gastrointestinal perforation. In present study, total 217 cases of perforation peritonitis is studied in which upper gastrointestinal perforations are found most common. In whole gastrointestinal tract most common site of perforation is found at duodenum, followed by ileum, gastric, appendicular, jejunal and colonic.
A study of total 504 cases of perforation peritonitis at Chandigarh done by Jhobta et al ${ }^{[15]}$ in 2006 over a period of 5 years was done. An another study of total 400 cases done at Lok Nayak Hospital Delhi ${ }^{[16]}$ in 2014 over a period of 3 years. These both studies are compared with present study on the basis of spectrum of perforation peritonitis in table 4 .

On comparison of all these studies it was found that gastroduodenal perforations is most common site in whole gastrointestinal tract. In gastroduodenal perforations duodenum is most common site to be perforated in all cases of perforation peritonitis. After gastroduodenal site, perforation are found commonly on ileum followed by appendicular, jejunal and colonic perforations. So on the basis of spectrum of perforation peritonitis present study having almost same results on most common site of perforation which is duodenal, on comparison with previous studies in India and other tropical countries. Incidence for other sites of perforation may differ in various studies but are comparable.

More commonly the perforations involve the proximal part of gastrointestinal tract, this being in contrast to studies from the western countries, where perforation are common in the distal part. After exploration and finding site of perforation, surgical procedure is done which outcome totally depends on site of perforation, general condition of patient, comorbidities of patient and various other factors.

\section{CONCLUSION}

Perforation peritonitis is frequently encountered surgical emergency. In spectrum of perforation peritonitis in North West Rajasthan, most common site of perforation is duodenal followed by ileal, gastric and prepyloric, appendicular, jejunal and colonic. Mean age of presentation is $44.36 \pm 18.30$ years with highly male preponderance.

NSAIDs intake, alcohol consumption and smoking are responsible for most commonly encourntered gastroduodenal perforation in this 
region. Prevention of abuse of all these substances can considerably decrease the incidence of UGI perforations.

\section{BIBLIOGRAPHY}

1. Suanes C, Salvesan H, Espehang B. A multifactorial analysis of factors related to lethality after treatment of perforated gastrduodenal ulcer. Ann Surg 1989; 209:418-23.

2. Wittmann DH. Operative and nonoperative therapy of intra-abdominal infections. Infection. 1998; 26:335-341.

3. Doherty GM, Editor. Current diagnosis and treatment, Surgery. $13^{\text {th }}$ edition. New York: The McGraw-Hill Companies, Inc.; 2010:464-8.

4. Dorairajan LN, Gupta S, Deo SVS, Chumber S, Sharma L. Peritonitis in India-A decades experience. Trop Gastroenterol 1995; 16(1):33-38.

5. Crawfurd E, Ellis $\mathrm{H}$ : Generalised peritonitis-The changing spectrum. A report of 100 consecutive cases. Br J Clin Pract 1985; 5:177-78.

6. Washington BC, Villalba MR, Lauter CB. Cefamendole-erythromycin-heparin peritoneal irrigation. An adjunct to the surgical treatment of diffuse bacterial peritonitis. Surgery 1983; 94:576-81.

7. Nomikos IN, Katsouyanni K, Papaioannou AN. Washing with or without chloremphenicol in the treatment of peritonitis. A prospective clinical trial. Surgery 1986; 99:20-25.

8. Shinagawa N, Muramoto M, Sakurai S, Fukui T, Hon K, et al. A bacteriological study of perforated duodenal ulcer. Jap J Surg 1991; 21:17.

9. Levison ME, Bush LM. Intra-abdominal Infection. In Mandell, Bennett, \& Dolin's Principles and Practice of Infectious Diseases. In: Peritonitis and
Intraperitoneal Abscesses. 6th ed. Churchill Livingstone: An Imprint of Elsevier; 2005.

10. Simmen H, Heinzelmann M, Largiader F. Peritonitis classification and causes. Dig Surg. 1996; 13:381-3.

11. Malangoni MA, Inui T. Peritonitis - the Western experience. World J Emerg Surg. 2006; 1:25.

12. Agarwall N, Saha N, Srivastava A, Chumber S, Dhar A, Garg S. Peritonitis 10 years experience in a simple surgical unit. Trop Gastroenterol. 2007; 28(3):117-20.

13. Schein M. Surgical management of intraabdominal infection: is there any evidence? Langenbecks Arch Surg. 2002; 387(1):1-7.

14. Afridi SP, Malik F, Ur-Rahman S, Shamim S, Samo KA. Spectrum of perforation peritonitis in Pakistan: ses Eastern experience. World J Emerg Surg. 2008; 3:31.

15. Jhobta RS, Attri AK, Kaushik R, Sharma R, Jhobta A. Spectrum of perforation peritonitis in India-review of 504 consecutive cases. World J Emerg Surg. 2006; 1:26.

16. Bali RS, Verma S, Agarwal PN, Singh R, Talwar N. Perforation peritonitis and the developing world. ISRN Surg. 2014; 2014:105492. 